\section{Comparative Physiology of Natural Deacclimation in Ten Azalea Cultivars}

\author{
Bing Liu
}

Department of Horticulture, College of Agriculture and Biotechnology, Physiology and Molecular Biology Laboratory of Ornamental Plants, Zhejiang University, Zhejiang, 866 Yuhangtang Road, Hangzhou, 310058, Peoples's Republic of China; and Department of Horticulture, Iowa State University, Ames, IA 50010

\section{Hong Zhou, Sha Cao, and Yi-ping Xia ${ }^{1}$}

Department of Horticulture, College of Agriculture and Biotechnology, Physiology and Molecular Biology Laboratory of Ornamental Plants, Zhejiang University, Zhejiang, 866 Yuhangtang Road, Hangzhou, 310058, People's Republic of China

\section{Rajeev Arora ${ }^{1}$ \\ Department of Horticulture, Iowa State University, Ames, IA 50010}

Additional index words. Rhododendron, Tsutsusi, cold acclimation, freezing tolerance, total soluble sugars, starch

\begin{abstract}
Seasonal deacclimation was investigated during Jan. to Mar. 2014 in leaves of 10 azalea cultivars (Rhododendron section Tsutsusi) under natural conditions in eastern China. Based on the midwinter leaf freezing tolerance (LFT), these cultivars were grouped as "more-hardy" vs. "less-hardy." Eight of the 10 cultivars first showed deacclimation when daily mean temperature over 2-week period preceding the LFT measurement was $\approx 9.5^{\circ} \mathrm{C}$. Deacclimation for other two cultivars was somewhat delayed and might have involved deacclimation-reacclimation cycling before eventual deacclimation. Our data indicate that the "more-hardy" group deacclimated slower than the "less-hardy" ones over the first half of the deacclimation period. This trend reversed during the second half of the deacclimation period. Accordingly, "more-hardy" and "less-hardy" cultivars depicted a "curvilinear" and "reverse curvilinear/linear" deacclimation kinetics. "More-hardy" cultivars generally had higher total soluble sugars (TSS) than "less-hardy" ones at acclimated state. TSS declined during deacclimation in all cultivars, and the loss was positively correlated with the loss in LFT. Leaf starch content generally followed opposite trend to that of TSS, i.e., it was at lowest during acclimated state and increased during deacclimation.
\end{abstract}

Geographical distribution of plants in temperate climates is determined by their ability to survive extended periods of subfreezing temperatures. Woody perennials in such climates are able to do so by acquiring a gradual, seasonal increase in their freezing tolerance (FT) via a process called cold acclimation which is induced by exposure to short days and cooler temperatures in autumn (Arora et al., 1992). This induced FT is then lost via a process called deacclimation when warmer temperatures return during spring (Kalberer et al., 2006). Deacclimation occurs irreversibly and at a much faster rate when plants are no longer endodormant

Received for publication 7 June 2017. Accepted for publication 9 Aug. 2017.

This research was supported by funds from Zhejiang Province, China (Project- "The evaluation of germplasm resources and variety breeding of azaleas"-2016C02056-12) and Iowa Agriculture and Home Economics Experiment Station, Ames, Iowa, Project No. 3601.

${ }^{1}$ Corresponding authors. E-mail: rarora@iastate.edu or ypxia@zju.edu.cn. (i.e., chilling requirement is met) and spring phenology has been triggered by warm temperatures (i.e., ecodormancy is broken) (Arora and Taulavuori, 2016; Kalberer et al., 2007a; Lang, 1987; Taulavuori et al., 1997). By contrast, a reversible and somewhat partial deacclimation can occur in response to unseasonal warm spells during midwinter or early spring (Ogren, 1996; Rapacz, 2002; Rowland et al., 2005; Strimbeck et al., 1995). Such premature and untimely deacclimation renders plants vulnerable to freeze injury by abrupt return of freezing temperatures (Pagter and Arora, 2013). However, plants that are capable of reacclimating (partially or fully reacquiring the lost FT) may be able to survive returning cold spells (Kalberer et al., 2007b; Pagter and Williams, 2011). Despite a significant role that deacclimation (speed and the extent) plays in winter survival of plant species, little is known about its physiology and kinetics for many economically important horticultural species.

The processes of cold acclimation and deacclimation are inherently complex involving a myriad of physiological, biochemical, and gene expression changes impacting carbohydrate metabolism, antioxidant status, membrane fluidity, levels of stress proteins, compatible solutes and hormones, etc. (Gusta and Wisniewski, 2013; Pagter and Arora, 2013; Xin and Browse, 2000). Soluble carbohydrates have often been associated with FT transitions, both seasonal as well as under controlled environment, in various tissues of woody species in that they accumulate during cold acclimation and decrease during deacclimation (Pagter et al., 2008, 2011 and references therein). To the best of our knowledge, only three studies have investigated leaf soluble carbohydrates during a seasonal cold acclimation/deacclimation in woody species; the first two with broadleaved evergreens, one with olive (Eris et al., 2007) and the other with a woody liana, Hedera helix (Parker, 1962), however, the third study focused on red pine needles (Pomeroy et al., 1970).

Evergreen azaleas belong to the genus Rhododendron section Tsutsusi (Chamberlain and Rae, 1990) and, in China, are distributed mainly in the south of the Yangtze River. These woody ornamentals cease visible growth during winter (Wilkinson and Richards, 1991) and bloom in late March to early April as the spring flowering shrubs. However, frequent occurrences of milder winters or extreme temperature fluctuations in early spring in eastern China (as per data from Hangzhou's climate station) can adversely affect winter survival of many azalea cultivars because such conditions can result in inadequate cold acclimation or premature deacclimation. For example, in 2011, two warm spells occurred in January and/or February with the maximum air temperature of 15 to $20^{\circ} \mathrm{C}$ and daily mean above $10{ }^{\circ} \mathrm{C}$. Similar warm spells have occurred in 2013 , 2015, 2016, and 2017 (data not shown). It is, therefore, important to study deacclimation physiology of these azalea cultivars to natural fluctuations in air temperature. No such work has been conducted on this group of azaleas to the best of our knowledge. The present study was designed to investigate changes in the LFT during seasonal deacclimation (midwinter to early spring) of 10 azalea cultivars.

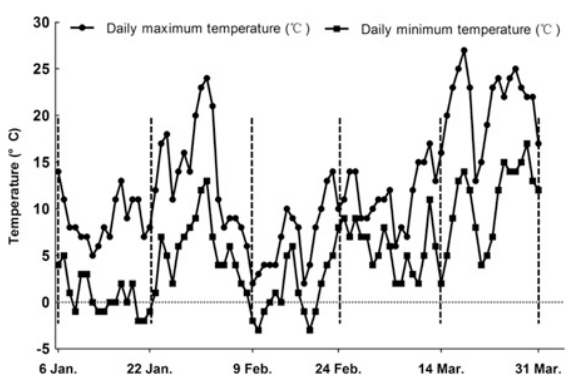

Fig. 1. Changes in the daily maximum and minimum temperatures at the experimental site from 6 Jan. to 31 Mar. 2014. Black dashed lines indicate the exact sampling dates (6 Jan. 22 Jan., 9 Feb., 24 Feb., 14 Mar., and 31 Mar.) for this experiment. 


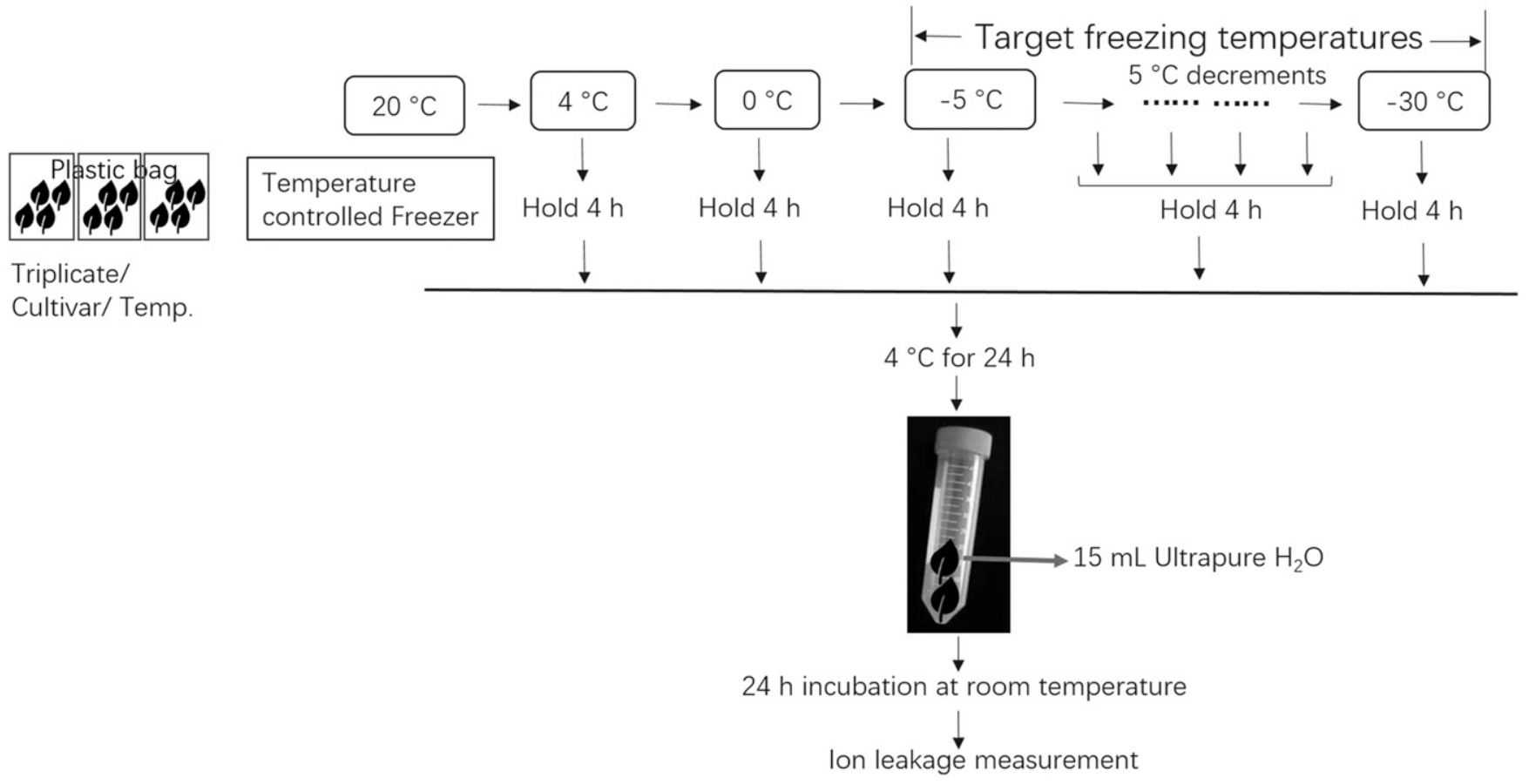

Fig. 2. Flow-sheet diagram of freeze-thaw protocol employed to assess leaf freezing tolerance of azaleas.

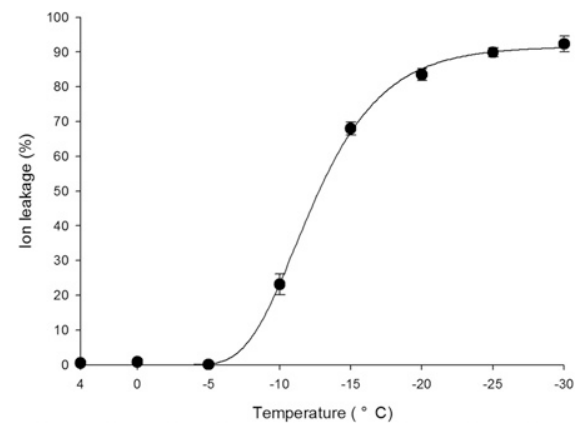

Fig. 3. Freeze-thaw injury sigmoid response for leaves of 'Zihudie' on 9 Feb. 2014, using Gompertz function. $\mathrm{LT}_{50}$, a midpoint (46.2\%) between the minimum $(0 \%)$ and maximum $(\approx 92.4 \%$ ) injury, is the temperature causing $50 \%$ injury and defined as leaf freezing tolerance (LFT).

Experiments were also conducted to determine their corresponding levels of carbohydrates (total soluble sugars and starch) to explore any correlations between the changes in these carbohydrates and deacclimation kinetics.

\section{Materials and Methods}

Plant material and sampling environment. The experiment was conducted using 2-year-old clonally propagated plants (from cuttings) of 10 evergreen azalea cultivars, 'Changchunerhao', 'Dazhusha', 'Elsie Lee', 'Hongshanhu', 'Nuccio's Pink Bobble', 'Shiyandujuan, 'Yudaizhirong', 'Zhuangyuanhong', 'Zihudie', and 'Zi'e'. No information is available on the precise species to which these cultivars belong but most likely these are complex interspecific hybrids developed by the local gardeners. They were planted in 3.79-L pots containing peat, pine needles, and yellow clay ( $3: 1: 1$ by volume) and maintained outside in a field nursery located in Hangzhou, Zhejiang Province $\left(30^{\circ} 15^{\prime} \mathrm{N}, 120^{\circ} 10^{\prime} \mathrm{E}\right)$.

Local air temperatures were obtained from Hangzhou climate station (Fig. 1). In this area, January, usually the coldest month of the year, was regarded as the midwinter time point, i.e., cold acclimated stage. The winter of 2014 was somewhat unusual because of unseasonal warm spells in January. The daily mean temperature during 6 to 22 Jan. was around $5{ }^{\circ} \mathrm{C}$, and the minimum air temperature of $-2.0{ }^{\circ} \mathrm{C}$ occurred on $20 \mathrm{Jan}$. Thereafter, the temperature began to rise from 23 Jan. onwards with an occurrence of $\approx+24{ }^{\circ} \mathrm{C}$ by the end of January to early February (2 Feb.). During this spell daily mean temperature was $\approx 12{ }^{\circ} \mathrm{C}$. Thereafter, daily mean temperature dropped to $\approx+5{ }^{\circ} \mathrm{C}$ between 3 Feb. and 9 Feb. with temperature dipping down to $-2{ }^{\circ} \mathrm{C}$ on the night of $8 / 9 \mathrm{Feb}$. Overall, there were $7 \mathrm{~d}$ with daily mean temperatures above $10{ }^{\circ} \mathrm{C}$ during 7 Jan. to 24 Feb. In March, the daily mean temperatures generally increased.

Fully expanded leaves from the current year growth were collected about every $15 \mathrm{~d}$, i.e., on 6 Jan., 22 Jan., 9 Feb., 24 Feb., 14 Mar., and 31 Mar. 2014. Sampling for each cultivar was made from 20 plants, separated into three biological replication blocks $(n=3)$, each containing six to seven plants. Two to eight leaves, depending on the leaf size, were randomly collected (to make $0.3 \mathrm{~g}$ sample) from each biological replication block for freezing tests. The leaves used to determine FT $\left(\mathrm{LT}_{50}\right)$ (see below) were used right after sampling whereas others were frozen in liquid nitrogen and stored at $-80{ }^{\circ} \mathrm{C}$ until biochemical analysis.

Freeze-test (determination of $L T_{50}$ ). Three biological replicates (of two to eight leaves each) per cultivar were randomly sampled, quickly rinse blotted, and placed into a plastic bag; air was squeezed from the sample bags before sealing. A total of 24 sample bags per cultivar, i.e., triplicate for each target temperature $(n=3)(4,0,-5,-10$, $-15,-20,-25$, and $-30{ }^{\circ} \mathrm{C}$ ) were placed in an ethanol freezing bath. The leaves were exposed to a stepwise lowering of temperature and holding for $4 \mathrm{~h}$ at each target temperature before removing from the bath to thaw at $4{ }^{\circ} \mathrm{C}$ for $24 \mathrm{~h}$ (Fig. 2). Samples exposed to $4{ }^{\circ} \mathrm{C}$ served as unfrozen control (UFC). Thawed and UFC samples were immersed in $15-\mathrm{mL}$ ultrapure water and vacuum infiltrated. After a quick vortex of tubes, the first ion leakage ( IL $_{\text {frozen }}$ ) was made after 24-h incubation at room temperature with a DDS-12A sensor (STARTER 3C; OHAUS, Shanghai, China). Samples were then heat killed at $100{ }^{\circ} \mathrm{C}$ for $30 \mathrm{~min}$ to allow the maximum ion leakage, and the second ion leakage ( $\mathrm{IL}_{\text {heat-killed }}$ ) was determined at room temperature. The ion leakage ratio (ILR) was calculated as

$$
\mathrm{ILR}=\left[\mathrm{IL}_{\text {frozen }} / \mathrm{IL}_{\text {heat-killed }}\right] \times 100 \%
$$

The injury percent (below) at each target temperature was calculated as per Lim and Arora (1998):

$$
\begin{aligned}
\operatorname{Injury}(\%)= & {\left[\operatorname{ILR}_{\text {target temperatue }}\right.} \\
& \left.- \text { Average }\left(\operatorname{ILR}_{\mathrm{UFC}}\right)\right] /[(100 \\
& \left.- \text { Average }\left(\operatorname{ILR}_{\mathrm{UFC}}\right)\right] \times 100
\end{aligned}
$$

Measurement of TSS and starch. TSS and starch were measured according to a previously described method (Laurentin 
Table 1. Freezing tolerance changes in leaf tissues of 10 azalea cultivars during 6 Jan. to 31 Mar. 2014. Data were calculated using asymmetric sigmoid (Gompertz) function (see Methods).

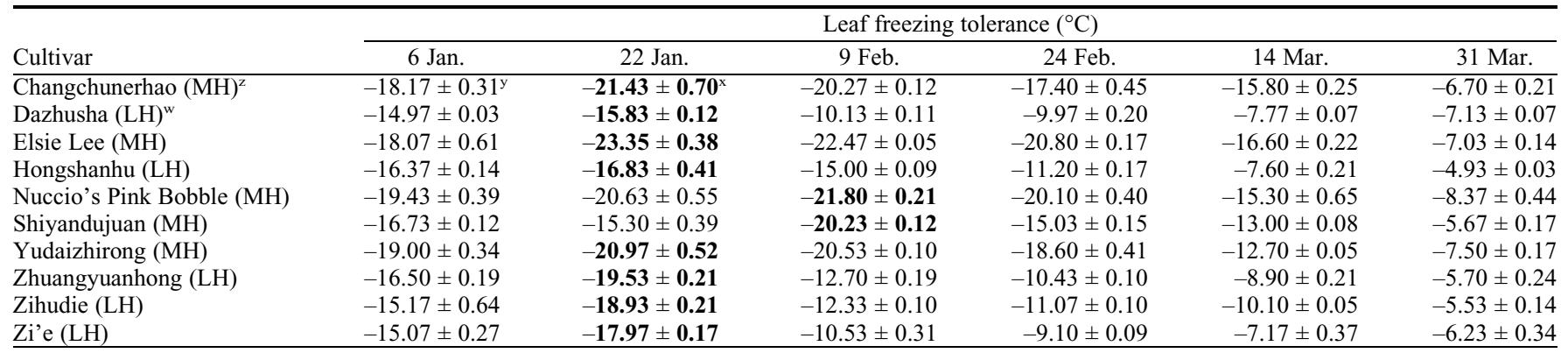

${ }^{\mathrm{z}}$ Cultivars with midwinter $\mathrm{LT}_{50}<-20{ }^{\circ} \mathrm{C}$ were grouped as "more-hardy" (MH).

${ }^{\mathrm{y}}$ Values are mean $\pm \mathrm{SE}$ of three biological replicates (see Methods).

${ }^{\mathrm{x}}$ Highest (most negative) $\mathrm{LT}_{50}$ during midwinter in each cultivar shown in bold.

${ }^{\text {w}}$ Cultivars with midwinter $\mathrm{LT}_{50} \geq-20{ }^{\circ} \mathrm{C}$ were grouped as "less-hardy" (LH).

Table 2. Rates of deacclimation in leaf tissues of 10 azalea cultivars. For the calculation of deacclimation rate (DR), entire deacclimation duration (22 Jan. to 31 Mar.) was divided in two equal periods, 22 Jan. to $24 \mathrm{Feb}$. and $24 \mathrm{Feb}$. to $31 \mathrm{Mar}$.

\begin{tabular}{lcc}
\hline & \multicolumn{2}{c}{ De-acclimation rate $^{\mathrm{z}}\left({ }^{\circ} \mathrm{C} \cdot \mathrm{d}^{-1}\right)$} \\
\cline { 2 - 3 } Cultivar & 22 Jan. to 24 Feb. & 24 Feb. to 31 Mar. \\
Slow deacclimation followed by fast de-acclimation & $0.08^{\mathrm{y}}$ & $0.39^{\mathrm{x}}$ \\
Elsie Lee & 0.05 & 0.34 \\
Nuccio's Pink Bobble & 0.07 & 0.32 \\
Yudaizhirong & 0.12 & 0.31 \\
Changchunerhao & 0.16 & 0.27 \\
Shiyandujuan & $0.17^{\mathrm{y}}$ & $0.18^{\mathrm{x}}$ \\
Fast deacclimation followed by slow de-acclimation & 0.18 & 0.08 \\
Hongshanhu & 0.24 & 0.16 \\
Dazhusha & 0.28 & 0.14 \\
Zihudie & 0.27 & 0.08 \\
Zhuangyuanhong & & \\
Zi'e & & \\
\hline
\end{tabular}

${ }^{\mathrm{z}}$ Deacclimation (DA) rates were calculated as $\Delta \mathrm{LFT} / \Delta$ time, where $\Delta \mathrm{LFT}$ is the difference between $\mathrm{LT}_{50}$ values on two sampling dates and $\Delta$ time is the number of intervening days. For example, $\Delta$ LFT between 22 Jan. and $24 \mathrm{Feb}$. for 'Changchunerhao' was $4.03{ }^{\circ} \mathrm{C}$; $\Delta$ time for this interval was $33 \mathrm{~d}$; thus, the DA rate is $4.03{ }^{\circ} \mathrm{C} / 33 \mathrm{~d}=0.12{ }^{\circ} \mathrm{C} \cdot \mathrm{d}^{-1}$.

${ }^{\mathrm{y}}$ During 22 Jan. to $24 \mathrm{Feb}$., DRs in 10 cultivars ranged from 0.05 to $0.28^{\circ} \mathrm{C} \cdot \mathrm{d}^{-1}$. DR of $<0.17^{\circ} \mathrm{C} \cdot \mathrm{d}^{-1}$, i.e., the midpoint of this range, was referred as "slow DA" whereas $\geq 0.17^{\circ} \mathrm{C} \cdot \mathrm{d}^{-1}$ as "fast DA."

${ }^{\mathrm{x}}$ During $24 \mathrm{Feb}$. to $31 \mathrm{Mar}$., DRs in 10 cultivars ranged from 0.08 to $0.39^{\circ} \mathrm{C} \cdot \mathrm{d}^{-1}$. DR of $<0.24{ }^{\circ} \mathrm{C} \cdot \mathrm{d}^{-1}$, i.e., the midpoint of this range, was referred as "slow DA" whereas $\geq 0.24^{\circ} \mathrm{C} \cdot \mathrm{d}^{-1}$ as "fast DA."

and Edwards, 2003; McCready et al., 1950) with slight modifications. About $0.3 \mathrm{~g}$ of fresh weight was ground in $5 \mathrm{~mL}$ of $80 \%$ ice-cold ethanol $(\mathrm{v} / \mathrm{v})(n=3)$. The slurry was centrifuged at $4000 \mathrm{rpm}$ for $5 \mathrm{~min}$. This step was repeated thrice, and resultant supernatants were combined and used to determine TSS concentrations. Leftover sediments were mixed with $52 \%$ perchloric acid and centrifuged at $4000 \mathrm{rpm}$ for $30 \mathrm{~min}$. This step was repeated twice, and resultant supernatants were combined and used to determine starch. The TSS and starch contents were determined using the colorimetric anthrone-sulfuric acid method. Glucose was used as standard. Five hundred microliter sample (TSS or starch extractions) $+500 \mu \mathrm{L}$ distilled water $+10 \mathrm{~mL}$ anthrone was heated at $100{ }^{\circ} \mathrm{C}$ for $10 \mathrm{~min}$, and then cooled to room temperature in dark. Absorbance was determined at $620 \mathrm{~nm}$ using 1510 spectrophotometer (Spectrophotometer 1510-02046; Thermo Fisher Scientific Oy, Vantaa, Finland).

Statistical analyses. Leaf freezing tolerance, defined as the temperature causing $50 \%$ injury $\left(\mathrm{LT}_{50}\right)$, was calculated by fitting the injury percent at each target temperature to
Gompertz sigmoid function (Lim and Arora, 1998) (Fig. 3). The polynomial regression equations of LFT were processed by using Excel 2016. Deacclimation rates were calculated as $\Delta \mathrm{LFT} / \Delta$ time, where the numerator denoted the difference between $\mathrm{LT}_{50}$ values for two sampling dates and denominator the intervening days. One-way analysis of variance (ANOVA) was conducted to determine the significant differences between LFT and physiological parameters. Differences between treatments were tested using Fisher's least significant difference tests at the $5 \%$ significance level. Pearson's correlation was used to determine correlation coefficients.

\section{Results}

LFT at cold acclimated state and during de-acclimation time-line. Essentially, all cultivars further gained in LFT from 6 Jan. through 22 Jan. although some by relatively more than others (Table 1). By 22 Jan., however, eight of the 10 cultivars (except 'Nuccio's Pink Bobble' and 'Shiyandujuan') had attained maximal cold acclimation whereas the two exceptions did so by 9 Feb. sampling (Table 1). The most freeze-tolerant azalea cultivar in this study based on the cold acclimated/midwinter LFT was 'Elsie Lee' with an $\mathrm{LT}_{50}$ of $-23.35{ }^{\circ} \mathrm{C}$ on $22 \mathrm{Jan}$. We placed the 10 cultivars in two general categories based on their midwinter LFT: 1) "more-hardy" group with LFT colder than $-20{ }^{\circ} \mathrm{C}$ ('Elsie Lee', 'Nuccio's Pink Bobble', 'Changchunerhao', 'Yudaizhirong', and 'Shiyandujuan') and 2) "less-hardy" group with LFT lower than $-20^{\circ} \mathrm{C}$ ('Zhuangyuanhong', 'Zihudie', 'Zi'e', 'Hongshanhu', and 'Dazhusha') (Table 1).

Eight of the 10 cultivars began to deacclimate from 22 Jan. onwards whereas 'Nuccio's Pink Bobble', and 'Shiyandujuan' did so from 9 Feb. onwards through 31 Mar. (Table 1). Statistical analyses of the deacclimation response revealed distinct periods when the loss of LFT in certain cultivars was more pronounced than at other periods. For example, during 22 Jan. to 9 Feb., 'Dazhusha', 'Zhuangyuanhong', 'Zihudie', and ' $Z i$ 'e' lost their LFT by $36 \%, 35 \%$, $35 \%$, and $41 \%$, respectively, whereas their de-acclimation was $\approx 2 \%, 18 \%, 10 \%$, and $14 \%$ during $9 \mathrm{Feb}$. to $24 \mathrm{Feb}$. These four cultivars exhibited LFT loss of $22 \%, 15 \%$, $9 \%$, and $21 \%$ during $24 \mathrm{Feb}$. to $14 \mathrm{Mar}$., and $8 \%, 36 \%, 45 \%$, and $13 \%$, respectively, during the last sampling interval (14 Mar. to 31 Mar.) (Table 1). Similar variable deacclimation response can be gleaned for other six cultivars as well (Table 1).

De-acclimation kinetics and rates. Deacclimation rate (DR) was defined as the loss of LFT per day, and for this calculation, we divided the entire deacclimation duration into two halves, i.e., 22 Jan. to 24 Feb. and 24 Feb. to 31 Mar. During 22 Jan. to 24 Feb., the DRs in 10 cultivars ranged from 0.05 to $0.28^{\circ} \mathrm{C} \cdot \mathrm{d}^{-1}$. Cultivars with DRs of $<0.17^{\circ} \mathrm{C} \cdot \mathrm{d}^{-1}$, i.e., the midpoint of this range, were grouped as "slow deacclimators" whereas those with $\geq 0.17{ }^{\circ} \mathrm{C} \cdot \mathrm{d}^{-1}$ as "fast deacclimators." Accordingly, 'Changchunerhao', 'Elsie Lee', 'Nuccio's Pink Bobble', 'Shiyandujuan', and 'Yudaizhirong' were grouped as "slow deacclimators" during 22 Jan. to 24 Feb., whereas 'Dazhusha', 'Hongshanhu', 'Zhuangyuanhong', 'Zihudie', and 'Zi'e' as 'fast deacclimators' (Table 2). During 24 Feb. to 31 Mar., however, 

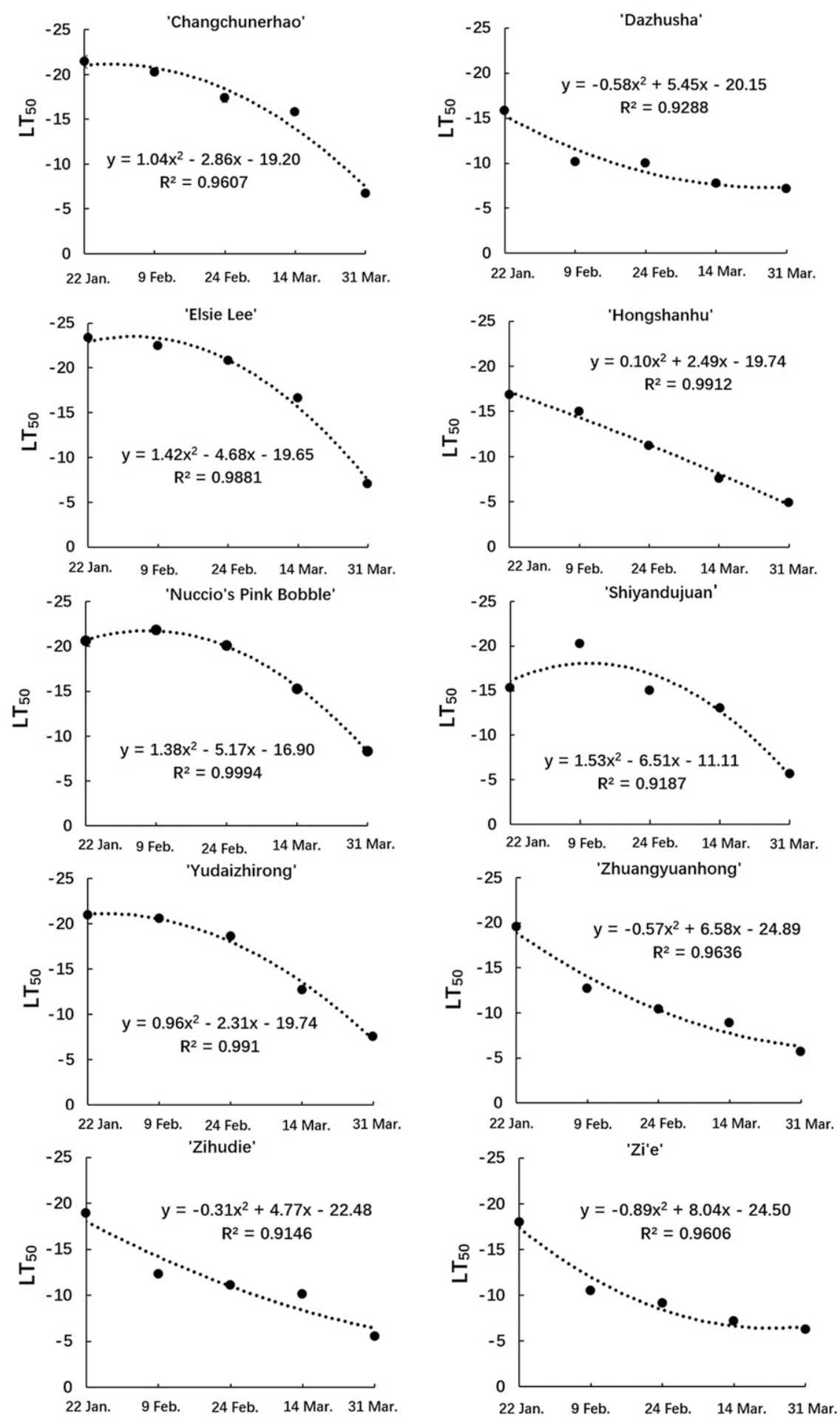

\section{De-acclimation Time-Course}

Fig. 4. Changes in leaf freezing tolerance $\left(\mathrm{LT}_{50} ;{ }^{\circ} \mathrm{C}\right)$ of 10 azalea cultivars and their regression equations during a deacclimation time course (22 Jan. to 31 Mar. 2014). $\mathrm{LT}_{50}$ changes fitted quadratic response with different regression equations. 6 Jan. sampling date was omitted in this figure because plants were still acclimating during 6 Jan. to 22 Jan.

the DRs in 10 cultivars were 0.08 to $0.39^{\circ} \mathrm{C} \cdot \mathrm{d}^{-1}$ (Table 2). Using the criterion defined previously, the first five cultivars ('Changchunerhao', 'Elsie Lee', 'Nuccio's Pink Bobble', 'Shiyandujuan', and 'Yudaizhirong') were grouped as "fast deacclimators" in this period, whereas the latter five ('Dazhusha',
'Hongshanhu', 'Zhuangyuanhong', 'Zihudie', and 'Zi'e') as "slow deacclimators" (Table 2).

We also used LFT data in EXCEL to derive polynomial regression equations and a graphical representation of deacclimation kinetics (Fig. 4). Our data indicate that the cultivars defined as "slow deacclimators" during 22 Jan. to 24 Feb. and "fast deacclimators" during 24 Feb. to 31 Mar. ('Changchunerhao', 'Elsie Lee', 'Nuccio's Pink Bobble', 'Shiyandujuan', and 'Yudaizhirong') exhibited a "curvilinear" response with an initial stationary phase followed by a relatively steep drop in LFT (Fig. 4). On the other hand, 'Dazhusha', 'Hongshanhu', 'Zhuangyuanhong', 'Zihudie', and 'Zi'e', categorized as "fast deacclimators" initially followed by relatively slow deacclimation, exhibited a "negative curvilinear or negative linear" deacclimation response with variable slopes (Fig. 4).

TSS and starch concentrations. Leaf TSS concentrations in 10 cultivars were at their maximum during 6 to 22 Jan.; eight of these cultivars had reached their maximum cold acclimation by 22 Jan. while two ('Nuccio's Pink Bobble' and 'Shiyandujuan') did so by the next sampling date ( 9 Feb.). Leaf TSS progressively declined during deacclimation, reaching their lowest by 31 Mar. (Fig. 5). TSS for the "more-hardy" group ranged from $95.7 \mathrm{mg} \cdot \mathrm{g}^{-1}$ (the highest of all 10 cultivars) to $74.7 \mathrm{mg} \cdot \mathrm{g}^{-1}$, averaging at 87.9 . By contrast, it ranged from 84.3 to $60.2 \mathrm{mg} \cdot \mathrm{g}^{-1}$ (the lowest of all) for the "less-hardy" group at an average of 75.8. Leaf TSS concentrations were positively correlated with LFT (Table 3).

Leaf starch concentration in 10 cultivars was relatively low during 6 Jan. to 9 Feb. (acclimated state), followed by a progressive increase during deacclimation reaching its maximum by 31 Mar. in all but two cultivars; 'Changchunerhao' and 'Hongshanhu' had highest leaf starch on 14 Mar. followed by a small reduction by 31 Mar. (Fig. 6). Starch concentration was negatively correlated with LFT for all but one cultivar (Table 3 ).

\section{Discussion}

$\mathrm{LT}_{50}$ has been a widely used parameter to define freezing tolerance of tissues in diverse herbaceous and woody species (Arora et al., 1992; Lim and Arora, 1998; Min et al., 2014; Pagter et al., 2008; Puhakainen et al., 2004; Rapacz, 2002). Using electrolyte-leakagebased $\mathrm{LT}_{50}$ as a measure of LFT and juxtaposing it on the climatic data (compare Table 1 and Fig. 1), our results indicate that none of the 10 cultivars should have been vulnerable to cold injury at the experimental site since their $\mathrm{LT}_{50} \mathrm{~s}$ ranged from $-23.35^{\circ} \mathrm{C}$ (highest cold hardiness for any cold acclimated sample) to $-4.93{ }^{\circ} \mathrm{C}$, the lowest among deacclimated samples; the lowest temperature at this site did not drop below $-4{ }^{\circ} \mathrm{C}$ at any time during the experiment. This interpretation, however, assumes that LFTs determined by laboratory-based freeze-thaw test in this study accurately predict field hardiness which may not necessarily be true. It must also be cautioned that these cultivars might have sustained some leaf damage under the minimum temperatures prevailing at the experimental site because $\mathrm{LT}_{50}$ only refers to the temperature causing 50\% injury. A 


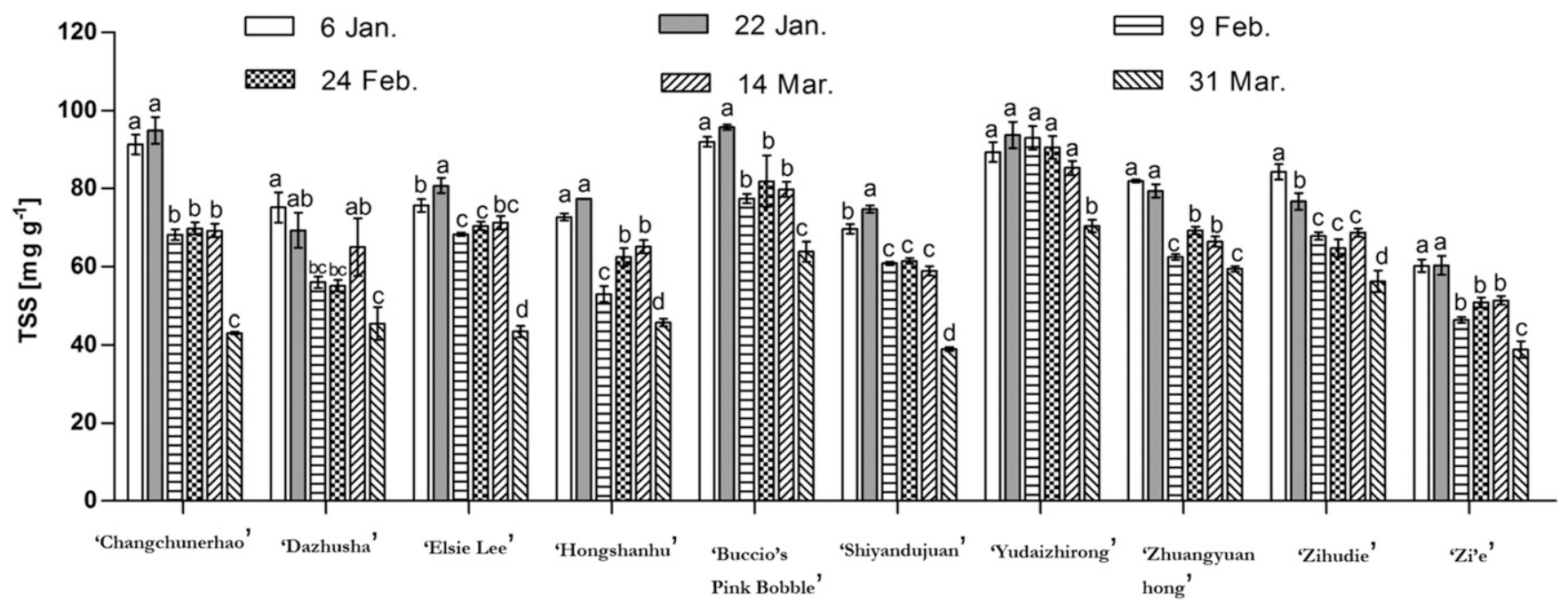

Fig. 5. Changes in concentrations of total soluble sugars (TSS) in leaf tissues of 10 azalea cultivars starting from 6 Jan. and ending on 31 Mar. 2014. Values are means \pm SE of three replicates. Different letters indicate significant differences across sampling dates but for the same cultivar, calculated by Fisher's least significant difference test $(P<0.05)$.

Table 3. Correlation coefficients between leaf freezing tolerance (LFT; $\mathrm{LT}_{50}$ ) and concentrations of total soluble sugars (TSS) and starch, as well as TSS vs. starch in leaf tissues of 10 azalea cultivars during 6 Jan. to 31 Mar. 2014.

\begin{tabular}{lccc}
\hline & \multicolumn{3}{c}{ Correlation coefficients } \\
\cline { 2 - 4 } Cultivars & LFT vs. TSS & LFT vs. starch & TSS vs. starch \\
\hline Changchunerhao & $0.84^{*}$ & $0.38 \mathrm{NS}$ & $-0.31 \mathrm{NS}$ \\
Dazhusha & $0.79 \mathrm{NS}$ & $-0.75 \mathrm{NS}$ & $-0.57 \mathrm{NS}$ \\
Elsie Lee & $0.90^{*}$ & $-0.93^{*}$ & $-0.94^{* *}$ \\
Hongshanhu & $0.67 \mathrm{NS}$ & $-0.85^{*}$ & $-0.29 \mathrm{NS}$ \\
Nuccio's Pink Bobble & $0.77 \mathrm{NS}$ & $-0.98^{* * *}$ & $-0.81^{*}$ \\
Shiyandujuan & $0.75 \mathrm{NS}$ & $-0.91^{* *}$ & $-0.92^{*} *$ \\
Yudaizhirong & $0.96^{* *}$ & $-0.91^{* *}$ & $-0.83^{*}$ \\
Zhuangyuanhong & $0.85^{*}$ & $-0.81^{*}$ & $-0.58 \mathrm{NS}$ \\
Zihudie & $0.86^{*}$ & $-0.79 \mathrm{NS}$ & $-0.63 \mathrm{NS}$ \\
Zi'e & $0.85^{*}$ & $-0.77 \mathrm{NS}$ & $-0.69 \mathrm{NS}$ \\
\hline
\end{tabular}

${ }^{\text {Ns No significant difference; }{ }^{*}, * *, * * *}$ significant at $P<0.05,0.01$, or 0.001 .

close examination of the raw percent injury data for 10 cultivars revealed that 9 of 10 cultivars exhibited only $3 \%$ to $9 \%$ injury during 9 to 24 Feb. interval which also included the last coldest night $\left(\approx-3{ }^{\circ} \mathrm{C}\right)$; 'Zi'e' cultivar sustained $13.8 \%$ injury on 24 Feb. sampling.

De-acclimation response. Our data on midwinter LFT place 10 cultivars into "more-hardy" vs. "less-hardy" categories. Moreover, our results indicate that these two groups exhibited different deacclimation kinetics and rates (Table 2; Fig. 4). "Morehardy" group ('Elsie Lee', 'Nuccio's Pink Bobble', 'Changchunerhao', 'Yudaizhirong', and 'Shiyandujuan') appears to be relatively more resistant to deacclimation during the first half of the deacclimation time line (22 Jan. to 24 Feb.) than the "less-hardy" group ('Dazhusha', 'Hongshanhu', 'Zhuangyuanhong', 'Zihudie', and 'Zi'e'). However, this trend reversed during the second half, i.e., "less-hardy" group deacclimated slower than the "more-hardy." Therefore, it appears that midwinter leaf hardiness and deacclimation resistance represent two distinct traits that are not necessarily linked. Fast or slow deacclimation response has been previously reported for buds of several azalea genotypes and ecotypes (Kalberer et al., 2007b) as well as other woody perennials, such as hydrangea (Pagter and Williams, 2011), blueberry (Arora et al., 2004), grapes (Wolf and Cook, 1992), and bilberry (Taulavuori et al., 2002).

Fast or slow deacclimation is likely a function of combination of factors, such as environment (temperature fluctuations), genotype, tissue type, dormancy status, all of which impinge on the physiology and thereby the threshold warming required for deacclimation (Arora and Taulavuori, 2016). Kalberer et al. (2007a) concluded that azalea buds were more resistant to deacclimation in the endodormant state and that this resistance declined as buds progressively accumulated chill units and transitioned to ecodormancy. Although, we did not evaluate chilling requirements or dormancy status of the azalea cultivars in this study, the higher or lower resistance to deacclimation particularly during $22 \mathrm{Jan}$. to $24 \mathrm{Feb}$. could be related to the dormancy status/chilling requirements of the two "hardiness" groups. However, this hypothesis could only be valid if the leaf deacclimation physiology of these cultivars was found to be related to, or influenced by, bud dormancy status, a topic of future investigations.

Eight of 10 cultivars (except 'Nuccio's Pink Bobble' and 'Shiyandujuan') showed deacclimation during 22 Jan. to 9 Feb. (Table 1) which might have been in response to abrupt warming (mean temperature $12{ }^{\circ} \mathrm{C}$ ) with temperatures rising up to $24^{\circ} \mathrm{C}$ on $2 \mathrm{Feb}$. (Fig. 1). This suggests that the threshold warming required to induce deacclimation was sufficient for these eight cultivars during this interval. By contrast, LFT of 'Nuccio's Pink Bobble' and 'Shiyandujuan' on 9 Feb. was even greater than on 22 Jan. Our climatic data (Fig. 1) reveal a cooling spell of few days during 4 to $9 \mathrm{Feb}$. with the daily mean temperature of $\approx+5{ }^{\circ} \mathrm{C}$ and the maximum and minimum ranging from +9 to $-2^{\circ} \mathrm{C}$. It is tempting to speculate that Nuccio's Pink Bobble and Shiyandujuan cultivars might have reacclimated in response to this brief but significant cooling (after some deacclimation) whereas for other eight cultivars either this cooling dose was not conducive for reacclimation or they were already predisposed to irreversible deacclimation. For 'Nuccio's Pink Bobble' and 'Shiyandujuan', deacclimation was first noticed on $24 \mathrm{Feb}$. There were four occurrences of the maximum temperatures ranging from 10 to $14{ }^{\circ} \mathrm{C}$ during the 2 weeks before 24 Feb. sampling, which might have been the driver for deacclimation in these two cultivars. Experiments using precisely controlled temperatures and samplings at smaller intervals for LFT estimation are needed in future studies to test this hypothesis. It is noteworthy though that 'Nuccio's Pink Bobble' and 'Shiyandujuan' also belong to the group that was deemed as "slow deacclimator" during 22 Jan. to 24 Feb. 'Nuccio's Pink Bobble' and 'Shiyandujuan' leaves began to finally deacclimate during 9 to $24 \mathrm{Feb}$. interval when the daily mean temperatures were around $+5^{\circ} \mathrm{C}$, suggesting the mean threshold temperature for deacclimation in these cultivars to be around 


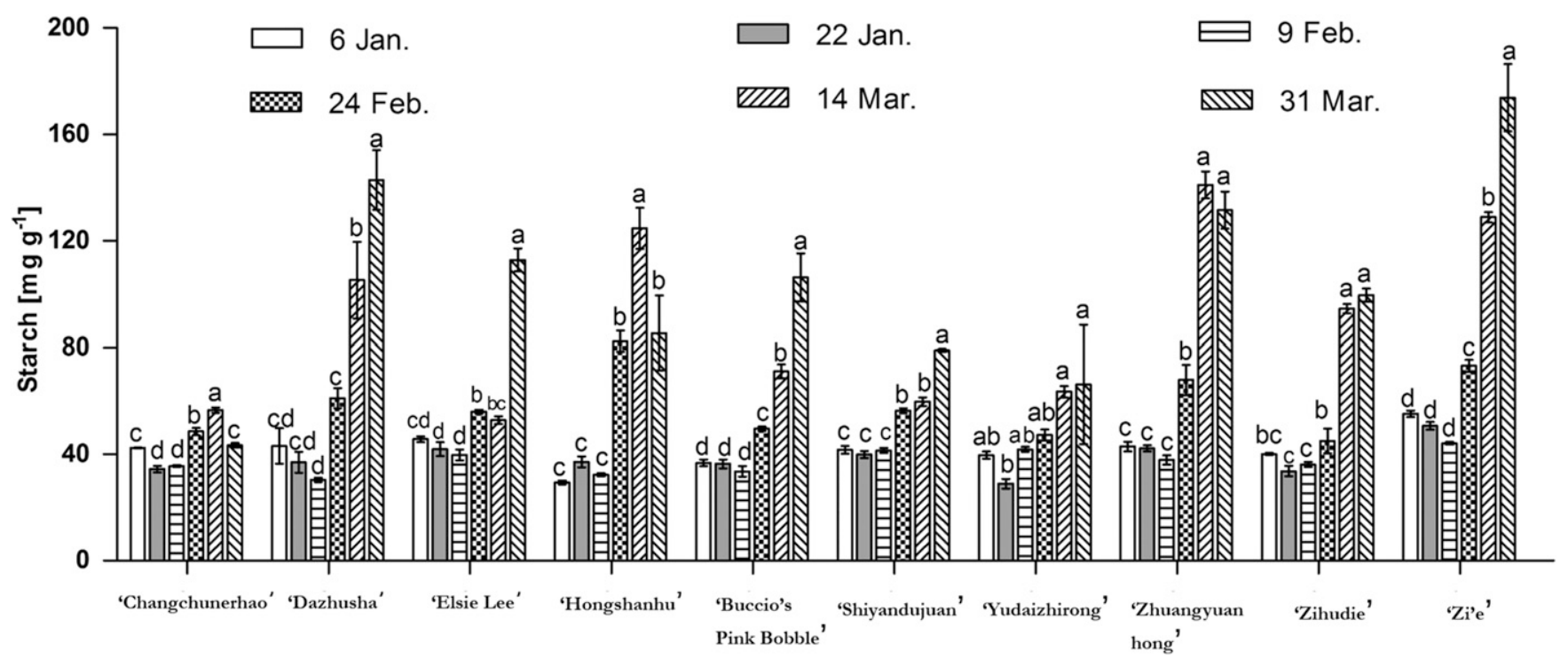

Fig. 6. Changes in concentrations of starch in leaf tissues of 10 azalea cultivars starting from 6 Jan. and ending on 31 Mar. 2014. Values are means \pm SE of three replicates. Different letters indicate significant differences across sampling dates but for the same cultivar calculated by Fisher's least significant difference test $(P<0.05)$.

$5{ }^{\circ} \mathrm{C}$. Similar results have been obtained for hydrangea stems (Pagter et al., 2011), poplar xylem (Sauter et al., 1996), and conifer shoots (Bigras et al., 2001).

From 24 Feb. onwards till the end of March, all cultivars continued to deacclimate by various degrees. Eight cultivars deacclimated most substantially during 14 Mar. to 31 Mar., i.e., by $35 \%$ to $58 \%$. By comparison, 'Dazhusha' and 'Zi'e' deacclimated by only $8 \%$ and $13 \%$, respectively. These varying degrees of deacclimation during this interval may be the reflection of different heat-unit requirements of these cultivars to overcome ecodormancy and/or differential physiological responses by leaves to warming. It has been widely reported that the greatest loss of freezing tolerance in spring coincides with the loss of ecodormancy and/or spring phenology/ bud break, presumably explained by altered physiology (increased cellular hydration, higher respiration leading to loss of sugars, hormonal changes, etc.) (Arora and Taulavuori, 2016 and references therein). Zhou et al. (2016) have recently reported that vegetative and floral budbreak in spring for most azaleas in Zhejiang region of China begins to occur around late February to late March, respectively.

LFT versus TSS and starch. In six of 10 cultivars, the concentration of TSS was highly correlated to LFT, suggesting a relatively important role of TSS in LFT in azaleas (Table 3; Fig. 5). Ours is only the second report to our knowledge to show changes in TSS and seasonal deacclimation in overwintering leaves of a woody shrub or tree. On the other hand, several studies have reported carbohydrate accumulation patterns in stem or bud tissues in relation to cold hardiness changes, both, seasonally and under controlled environment (Ashworth et al., 1993; Palonen, 1999; Pomeroy et al., 1970). Relatively recent studies on hydrangea stems reported accumulation patterns of individual sugars (glucose, sucrose, fructose, raffinose, kestose, galactose, etc.) during seasonal acclimation and deacclimation (Pagter et al., 2008, 2011). In all these studies, loss of TSS was positively correlated with deacclimation.

Our data reinforce previous observations and indicate a positive correlation between seasonal LFT and leaf TSS in 10 azalea cultivars (Table 3 ), with six of these more strongly correlated than the other four, i.e., 'Dazhusah', 'Hongshanhu', 'Nuccio's Pink Bobble', and 'Shiyandujuan'. Contrary to expectation, two of these four cultivars showed loss in TSS during 22 Jan. to 9 Feb. when LFT indeed increased. As discussed elsewhere in this article, we suggest such increased LFT in these two cultivars was perhaps a reflection of reacclimation after presumed partial deacclimation. Accordingly, we speculate that TSS accumulation perhaps lagged behind the change in LFT for these cultivars during 22 Jan. to $9 \mathrm{Feb}$. Similar lag in accumulation of sugars relative to changes in freezing tolerance of pine needles and bark has been previously observed (Pomeroy et al., 1970). Our data also indicate that TSS of "more-hardy" cultivars, in general, were higher than that of "lesshardy" group (Fig. 5). However, the hardier cultivars within each group did not always have higher TSS. Accumulation of sugars has been implicated in promoting freezing tolerance directly or indirectly; some have ascribed protection of cellular membranes from freeze-induced desiccation as being the role of sugars (Crowe et al., 1998; Hincha et al., 2002) whereas others have opined that sugars are needed as substrates for the synthesis of cryoprotectants (Klotke et al., 2004).

Our data indicate that increasing concentration of leaf starch generally coincided with the loss of LFT and reduction in TSS concentrations, suggesting sugar-starch conversion during deacclimation (Table 1; Figs. 5 and
6). This is further reinforced by the negative correlation between LFT vs. starch concentration and TSS vs. starch concentration data (Table 3). However, the two exceptions, 'Changchunerhao' and 'Hongshanhu', showed drop in leaf starch on the last sampling date compared with the previous sampling. Although reason for this is not clear, similar phenomenon was observed in Hydrangea stems (Pagter et al., 2008). Reversible seasonal sugar-starch accumulation patterns have been widely reported for stem or bud tissues of woody species (Pagter et al., 2008; Sauter and Cleve, 1991; Siminovitch et al., 1953). Ours is the only such report, other than that by Pomeroy et al. (1970) for pine needles, in overwintering leaves during deacclimation. Starch-sugar conversion could be brought about by differential activities/ amounts of starch degrading or sucrose synthesizing enzymes (amylases or sucrose phosphate synthase, respectively) as a function of changing temperatures during the seasonal cycle (Elle and Sauter, 2002; Schrader and Sauter, 2002). Examining the activity of these enzymes in the leaves of azalea cultivars along with photosynthesis response is needed to gain further insight into mechanistic basis of sugar vs. starch status. Wei et al. (2005) noted cold acclimated leaves of Rhododendron catawbiense to be highly enriched in beta amylase expressed sequence tags (ESTs) whereas nonacclimated/de-acclimated tissues were deficient in these transcripts. It suggests that starch is catabolized by amylases during winter into simple sugars which could serve as osmoprotectants and protect overwintering leaves from freeze desiccation.

In conclusion, our results indicate that leaves from 10 azalea cultivars used in this study could survive freezing stress by resisting deacclimation and that this trait may be helpful at different periods of overwintering cycle: "more-hardy" group may be well 
suited to survive hard frosts after unseasonal warm spells in midwinter, whereas those from "less-hardy" group could survive sudden frost in the early spring, a frequent occurrence in early March in this region. Moreover, leaves of "more-hardy" group are less prone to frost injury in early spring mainly because of their higher leaf-freezing tolerance. This information when reconciled with dormancy physiology and freezing tolerance of buds of these cultivars may provide valuable resource for breeding azalea cultivars that may be resilient to vagaries of climate.

\section{Literature Cited}

Arora, R., L.J. Rowland, E.L. Ogden, A.J. Dhanaraj, C.O. Marian, M.K. Ehlenfeldt, and B. Vinyard. 2004. De-hardening kinetics, bud development, and dehydrin metabolism in blueberry cultivars during de-acclimation at constant, warm temperatures. J. Amer. Soc. Hort. Sci. 129:667674.

Arora, R. and K. Taulavuori. 2016. Increased risk of freeze damage in woody perennials $V I S$ $\grave{A}$-VIS climate change: Importance of deacclimation and dormancy response. Front. Environ. Sci. 4:44.

Arora, R., M.E. Wisniewski, and R. Scorza. 1992. Cold acclimation in genetically related (sibling) deciduous and evergreen peach (Pruns persica [L.] Batsch). I. Seasonal changes in cold hardiness and polypeptides of bark and xylem tissues. Plant Physiol. 99:1562-1568.

Ashworth, E.N., V.E. Stirm, and J.J. Volenec. 1993. Seasonal variations in soluble sugars and starch within woody stems of Cornus sericea L. Tree Physiol. 14:379-388.

Bigras, F.J., A. Ryyppo, A. Lindstrom, and E. Stattin. 2001. Conifer cold hardiness, p. $57-$ 88. In: F.J. Bigras and S.J. Colombo (eds.). Cold acclimation and de-acclimation of shoots and roots of conifer seedlings. Springer Science + Business Media, Dordrecht, The Netherlands.

Chamberlain, D.F. and S.J. Rae. 1990. A revision of Rhododendron. IV Subgenus Tsutsusi. Edinb. J. Bot. 47(2):89-200.

Crowe, J.H., J.F. Carpenter, and L.W. Crowe. 1998. The role of vitrification in anhydrobiosis. Annu. Rev. Physiol. 60:73-103.

Elle, D. and J.J. Sauter. 2002. Seasonal changes of activity of a starch granule bound endoamylase and of a starch phosphorylase in poplar wood (Populus Xcanadensis Moench $<$ robusta>) and their possible regulation by temperature and phytohormones. J. Plant Physiol. 156:731-740.

Eris, A., H. Gulen, E. Barut, and A. Cansev. 2007. Annual patterns of total soluble sugars and proteins related to cold-hardiness in olive (Olea europaea L. 'Gemlik'). J. Hort. Sci. Biotechnol. 82(4):597-604.

Gusta, L.V. and M. Wisniewski. 2013. Understanding plant cold hardiness: An opinion. Physiol. Plant. 147:4-14.

Hincha, D.K., E. Zuther, E.M. Hellwege, and A.G. Heyer. 2002. Specific effects of fructo- and gluco- oligosaccharides in the preservation of liposomes during drying. Glycobiology 12(2): 103-110.

Kalberer, S.R., N. Leyva-Estrada, S.L. Krebs, and R. Arora. 2007a. Cold hardiness of floral buds of deciduous azaleas: De-hardening, re-hardening, and endodormancy in late winter. J. Amer. Soc. Hort. Sci. 132:73-79.

Kalberer, S.R., N. Leyva-Estrada, S.L. Krebs, and R. Arora. 2007b. Frost de-hardening and rehardening of floral buds of deciduous azaleas are influenced by genotypic biogeography. Environ. Expt. Bot. 59(3):264-275.

Kalberer, S.R., M. Wisniewski, and R. Arora. 2006. De-acclimation and re-acclimation of cold-hardy plants: Current understanding and emerging concepts. Plant Sci. 171:3-16.

Klotke, J., J. Kopka, N. Gatzke, and A.G. Heyer. 2004. Impact of soluble sugar concentrations on the acquisition of freezing tolerance in accessions of Arabidopsis thaliana with contrasting cold adaptation- evidence for a role of raffinose in cold acclimation. Plant Cell Environ. 27(11):1395-1404.

Lang, G.A. 1987. Endo-, para-, and eco-dormancy: Physiological terminology and classification for dormancy research. HortScience 22:371377.

Laurentin, A. and C.A. Edwards. 2003. A microtiter modification of the anthrone-sulfuric acid colorimetric assay for glucose-based carbohydrates. Anal. Biochem. 315(1):143-145.

Lim, C.C. and R. Arora. 1998. Comparing Gompertz and Richards functions to estimate freezing injury in Rhododendron using electrolyte leakage. J. Amer. Soc. Hort. Sci. 123:246-252.

McCready, R.M., J. Guggolz, V. Silviera, and H.S. Owens. 1950. Determination of starch and amylose in vegetables. Anal. Chem. 22(9):11561158.

Min, K., K.T. Chen, and R. Arora. 2014. Effect of short-term versus prolonged freezing on freezethaw injury and post-thaw recovery in spinach: Importance in laboratory freeze-thaw protocols. Environ. Expt. Bot. 106:124-131.

Ogren, E. 1996. Premature de-hardening in Vaccinium myrtillus during a mild winter: A cause for winter dieback? Funct. Ecol. 10:724-732.

Pagter, M. and R. Arora. 2013. Winter survival and de-acclimation of perennials under warming climate: Physiological perspectives. Physiol. Plant. 147(1):75-87.

Pagter, M., C.R. Jensen, K.K. Petersen, F. Liu, and R. Arora. 2008. Changes in carbohydrates, ABA and bark proteins during seasonal cold acclimation and de-acclimation in Hydrangea species differing in cold hardiness. Physiol. Plant. 134:473-485.

Pagter, M., I. Lefevre, R. Arora, and J.F. Hausman. 2011. Quantitative and qualitative changes in carbohydrates associated with spring deacclimation in contrasting Hydrangea species. Environ. Expt. Bot. 72:358-367.

Pagter, M. and M. Williams. 2011. Frost dehardening and re-hardening of Hydrangea macrophylla stems and buds. HortScience 48:1121-1126.

Palonen, P. 1999. Relationship of seasonal changes in carbohydrates and cold hardiness in canes and buds of three red raspberry cultivars. J. Amer. Soc. Hort. Sci. 124(5):507-513.

Parker, J. 1962. Relationships among cold hardiness, water-soluble protein, anthocyanins, free sugar in Hedera helix L. Plant Physiol. 37(6): 809-813.

Pomeroy, M.K., D. Siminovitch, and F. Wightman. 1970. Seasonal biochemical changes in the living bark and needles of red pine (Pinus resinosa) in relation to adaptation to freezing. Can. J. Bot. 48:953-967.
Puhakainen, T., M.W. Hess, P. Mäkelä, J. Svensson, P. Heino, and E.T. Palva. 2004. Overexpression of multiple dehydrin genes enhances tolerance to freezing stress in Arabidopsis. Plant Mol. Biol. 54:743-753.

Rapacz, M. 2002. Cold de-acclimation of Oilseed Rape (Brassica napus var. oleifera) in response to fluctuation temperatures and photoperiod. Ann. Bot. 89(5):543-549.

Rowland, L.J., E.L. Ogden, M.K. Ehlenfeldt, and B. Vinyard. 2005. Cold hardiness, deacclimation kinetics and bud development among 12 diverse blueberry genotypes under field conditions. J. Amer. Soc. Hort. Sci. 130:508-514.

Sauter, J.J. and B.V. Cleve. 1991. Biochemical and ultrastructural results during starch-sugarconversion in ray parenchyma cells of Populus during cold adaptation. J. Plant Physiol. 139(1): $19-26$.

Sauter, J.J., M. Wisniewski, and W. Witt. 1996. Interrelationships between ultrastructure, sugar levels, and frost hardiness of ray parenchyma cells during frost acclimation and deacclimation in poplar (Populus $\times$ canadensis Moench <robusta $>$ ) wood. J. Plant Physiol. 149:451-461.

Schrader, S. and J.J. Sauter. 2002. Seasonal changes of sucrose- phosphate synthase and sucrose synthase activities in poplar wood (Populus xcanadensis Moench <robusta $>$ ) and their possible role in carbohydrate metabolism. J. Plant Physiol. 159:833-843.

Siminovitch, D., C.M. Wilson, and D.R. Briggs. 1953. Studies on chemistry of the living bark of the black locust in relation to its frost hardiness. Seasonal transformations and variations in the carbohydrates: Starch-sucrose interconversions. Plant Physiol. 28(3):383-400.

Strimbeck, G.R., D.H. DeHayes, J.B. Shane, G.J. Hawley, and P.G. Schaberg. 1995. Midwinter de-hardening of montane red spruce during a natural thaw. Can. J. For. Res. 25:2040-2044.

Taulavuori, K., K. Laine, and E. Taulavuori. 2002. Artificial de-acclimation response of $\mathrm{Vacci}$ nium myrtillus (L.) in mid-winter. Ann. Bot. Fenn. 39:143-147.

Taulavuori, K., K. Laine, E. Taulavuori, T. Pakonen, and E. Saari. 1997. Accelerated de-hardening in Bilberry (Vaccinium myrtillus L.) induced by a small elevation in air temperature. Environ. Pollut. 98(1):91-95.

Wei, H., A.L. Dhanaraj, L.J. Rowland, Y. Fu, S.L. Krebs, and R. Arora. 2005. Comparative analysis of expressed sequence tags from cold-acclimated and non-acclimated leaves of Rhododendron catawbiense Michx. Planta 221:406-416.

Wilkinson, R.I. and D. Richards. 1991. Influence of paclobutrazol on growth and flowering of Rhododendron 'Sir Robert Peel'. HortScience 26:282-284.

Wolf, T.K. and M.K. Cook. 1992. Seasonal deacclimation patterns of three grape cultivars at constant, warm temperature. Amer. J. Enol. Viticult. 43(2):171-179.

Xin, Z. and J. Browse. 2000. Cold comfort farm: The acclimation of plants to freezing temperatures. Plant Cell Environ. 23:893-902.

Zhou, H., J. Liao, B. Liu, S. Cao, and Y.P. Xia. 2016. Effects of 5-azacytidine and gibberellic acid on flower development of azalea. Pak. J. Agr. Sci. 53(1):1-6. 